\title{
Effect of Silver on Secondary Recrystallization of 3 wt $\%$ Aluminum-Iron Alloy
}

\author{
By Mitsuo Imai*, Katsumi Fujimoto*, \\ Tatsuo Saito* and Jiro Hirata*
}

\begin{abstract}
Isothermal annealing of a $0.30 \mathrm{~mm}$ thick sheet of cold rolled $3 \mathrm{wt} \%$ aluminum-iron was conducted at $950^{\circ} \mathrm{C}$, in order to investigate the effect of silver on the secondary recrystallization behavior. By the addition of $0.018 \mathrm{wt} \%$ silver, the normal grain growth of the primary grains was effectively retarded and a strong Goss texture was developed by the secondary recrystallization. It is considered that such an element as silver which has a very low solid solubility in iron segregates preferentially at the grain boundary and thereby the free energy of activation for boundary migration of the matrix grains is increased.
\end{abstract}

(Received June 18, 1964)

\section{Introduction}

The role of impurities in the formation of the Goss texture in cold rolled silicon-iron has been investigated by many workers ${ }^{(1) \sim(4)}$. One of the authors ${ }^{(5)}$ carried out an extensive experiment on this problem, and suggested that impurity atoms of low solid solubility in iron would retard the normal growth of primary grains and promote the development of the Goss texture by a secondary recrystallization. This paper deals with an experimental study of cold rolled $3 \mathrm{wt} \%$ aluminum-iron to verify the above-mentioned proposal.

\section{Experimental Procedure}

Two alloys were melted in vacuum and cast into $4 \mathrm{~kg}$ ingots. Electrolytic iron and $99.9 \%$ aluminum were used as base materials to which silver was added as the impurity. Chemical analyses of the ingots are listed in Table 1. Sample No.l is a high-purity melt and sample No.2 a silver-containing melt.

Table 1 Chemical comfozition of materials.

\begin{tabular}{c|c|c|c|c|c|c|c}
\hline $\begin{array}{c}\text { Sample } \\
\text { No. }\end{array}$ & $\mathrm{C}$ & $\mathrm{Si}$ & $\mathrm{Mn}$ & $\mathrm{P}$ & $\mathrm{S}$ & $\mathrm{Al}$ & $\mathrm{Ag}$ \\
\hline 1 & 0.011 & 0.02 & 0.01 & 0.004 & 0.015 & 2.97 & $\mathrm{tr}$ \\
2 & 0.008 & $\mathrm{tr}$. & $\mathrm{tr}$. & 0.002 & 0.008 & 2.97 & 0.018 \\
\hline
\end{tabular}

The ingots, forged to $10 \mathrm{~mm}$ thick plates, were hot rolled by heating up to $950^{\circ} \mathrm{C}$ and then reduced to $2.0 \mathrm{~mm}$ thick sheets by reheating two times and then cooled in air. After pickling, they were cold rolled to an intermediate thickness of $0.60 \mathrm{~mm}$, annealed at $900^{\circ} \mathrm{C}$ for $5 \mathrm{~min}$ in air, and cold rolled to a final thickness of $0.30 \mathrm{~mm}$.

The final annealing was carried out for $10 \mathrm{~min}, 1 \mathrm{hr}$

* Technical Research Laboratory, Kawasaki Steel Corporation, Kche, Japan.

(1) W. Morrill: Met. Progress, 54(1948), 675 .

(2) J. D. Fast: Philips Repts., 11 (1956), 490.

(3) J. E. May and D. Trrnbull: Trans. AIME, 213 (1958), 769.

(4) E. V. Walker and J. Howard : J. Iron Steel Inst., 194 (1960), 96.

(5) T. Saito: J. Japan Inst. Metals, 27 (1963), 186.

Trans, J I M and $8 \mathrm{hr}$ at $950^{\circ} \mathrm{C}$ in nitrogen atmosphere.

All the specimens thus treated were subjected to metallographic observation, and the magnetic anisotropy was measured on the disks of $20 \mathrm{~mm}$ in diameter.

\section{Results}

In Photo.1 (a), (b) and (c) are shown structures of the high-purity melt recrystallized for $10 \mathrm{~min}, 1 \mathrm{hr}$ and $8 \mathrm{hr}$

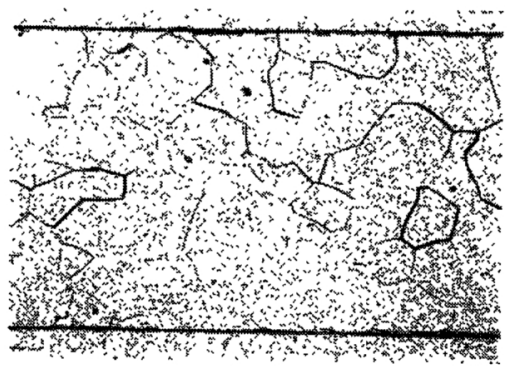

(a) $950^{\circ} \mathrm{C}, 10 \mathrm{~min}$

$\times 100$

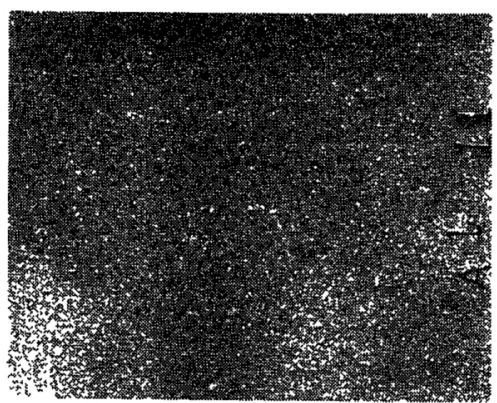

(b) $950^{\circ} \mathrm{C}, 1 \mathrm{hr}$

$\times 1$

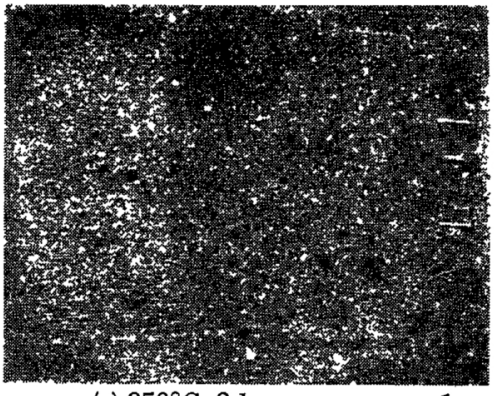

(c) $950^{\circ} \mathrm{C}, 8 \mathrm{hr}$

$\times 1$

Photo. 1 Structures of annealed $3 \mathrm{wt} \%$ aluminumiron containing no silver. 
at $950^{\circ} \mathrm{C}$ respectively. The mean diameter of recrystallized grains is $0.064 \mathrm{~mm}$ after a $10 \mathrm{~min}$ anneal at $950^{\circ} \mathrm{C}$ and increases to $0.066 \mathrm{~mm}$ after $1 \mathrm{hr}$. After an $8 \mathrm{hr}$ anneal the mean diameter of matrix grains is $0.10 \mathrm{~mm}$, and large grains of nearly the same linear dimension as the sheet thickness are found sporadically on the specimen surface. Therefore, it may be said that there is no secondary recrystallization.

In Photo. 2 (a), (b) and (c) are shown structures of the silver-containing melt. The mean diameter of recrystal-

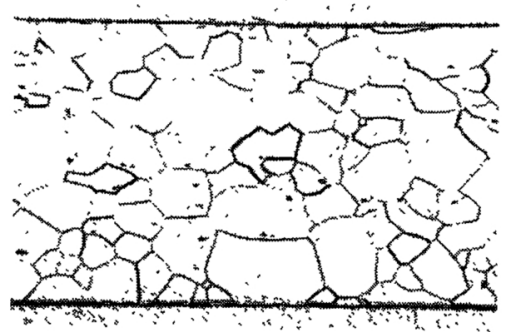

(a) $950^{\circ} \mathrm{C}, 10 \mathrm{~min}$

$\times 100$

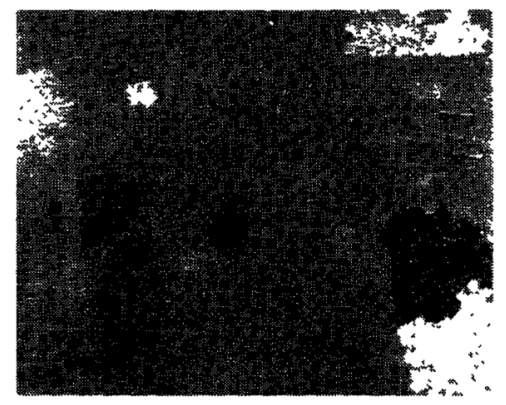

(b) $950^{\circ} \mathrm{C}, 1 \mathrm{hr}$ $\times 1$

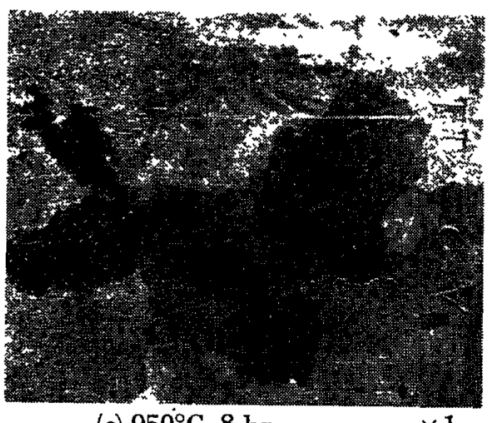

(c) $950^{\circ} \mathrm{C}, 8 \mathrm{hr}$

$\times 1$

Photo. 2 Structures of annealed $3 w t \%$ aluminumiron containing $0.018 \mathrm{wt} \%$ silver.

lized grains is $0.042 \mathrm{~mm}$ after a $10 \mathrm{~min}$ anneal at $950^{\circ} \mathrm{C}$. It grows to $0.052 \mathrm{~mm}$ after $1 \mathrm{hr}$ and about onethird of the specimen surface is occupied by large-size secondary grains. After the $8 \mathrm{hr}$ anneal, almost the entire specimen surface is covered with the secondary grains.

The torque curves are shown in Figs. 1 and 2. The torque peak values of the high-purity melt are low, while those of the silver-containing melt increase as the secondary recrystallization develops, and the specimen annealed for $8 \mathrm{hr}$ at $950^{\circ} \mathrm{C}$ has a torque curve analogous to that of the (110) [001] single crystal, showing a peak value of $24.2 \times 10^{4} \mathrm{ergs} / \mathrm{cm}^{3}$.

Cube poles of 15 grains selected at random from the silver-containing specimen annealed for $8 \mathrm{hr}$ at $950^{\circ} \mathrm{C}$ are plotted in Fig. 3, from which the specimen is known to have a Goss texture.

\section{Discussion}

The preceding results shows that the Goss texture by the secondary recrystallization in aluminum-iron alloy is developed by the addition of silver. It is considered

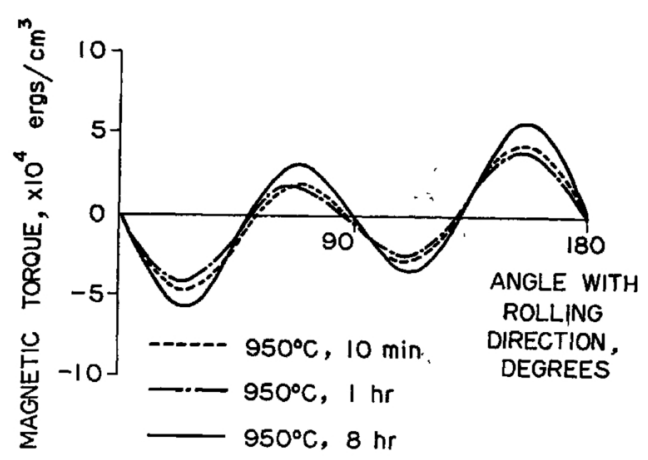

Fig. 1 Torque curves of anneald 3wt $\%$ aluminum iron containing no silver.

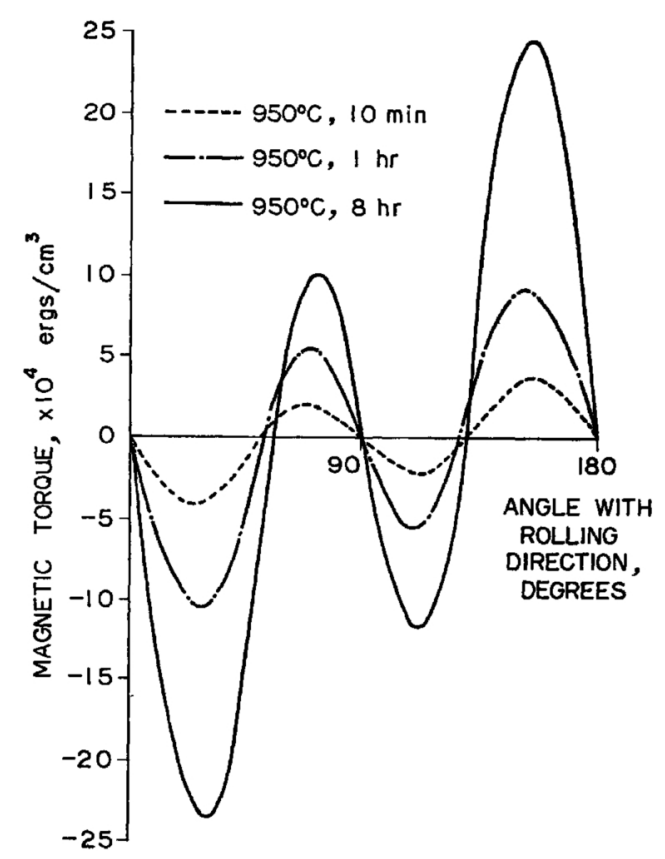

Fig. 2 Torque curves of annealed $3 w t \%$ aluminum iron containing $0.018 \mathrm{wt} \%$ silver.

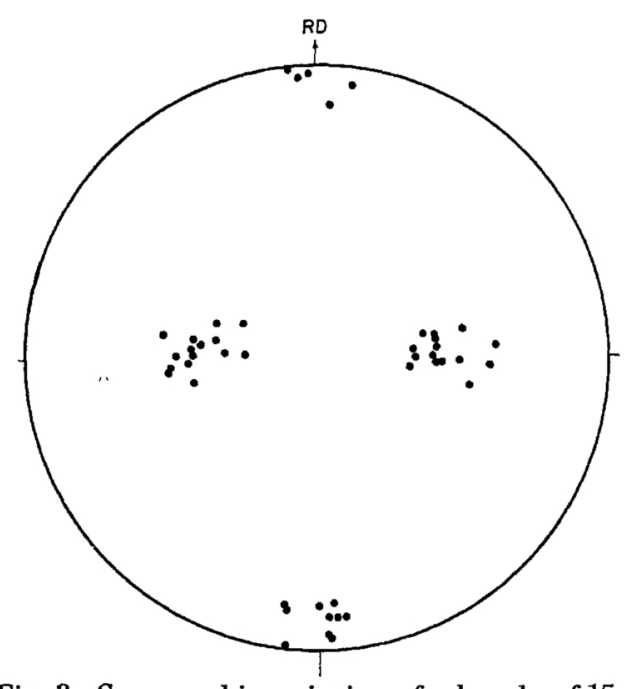

Fig. 3 Stereographic projections of cube poles of 15 grains in the silver-containing melt specimen annaled $8 \mathrm{hr}$ at $950^{\circ} \mathrm{C}$. 
that to obtain complete secondary recrystallization the primary matrix grains must be retained small in size as compared with the secondaries which eventually consume them. The normal growth of the primary grains was retarded more effectively in the silver-containing melt Photo. 2 (a) than in the high-purity melt Photo. 1 (a). It is an interesting phenomenon that the growth of primary grains would be suppressed by the addition of such a small quantity of silver. This observation is in good agreement with the recent work by one of the authors $^{(5)}$ and also with a theoretical calculation by Lücke and Detert ${ }^{(6)}$ that shows the addition of ahout 0.01 at $\%$ of solute to be sufficient to prevent a rapid boundary migration.

It appears well established that silver is insoluble in solid iron. However, from resistance measurements of iron-rich silver alloys prepared by sintering powder at $950^{\circ} \mathrm{C}$, some workers ${ }^{(7)}$ demanded the solid solubility of silver in iron to be $0.5 \sim 1.0 \mathrm{wt} \%$. From the dilatation curves some workers showed that the temperature of the alpha-gamma transformation of iron was lowered, indicating a certain degree of solid solubility ${ }^{(8)}$.

The primary solid solubility is greatly limited in case the disparity in atomic radii exceeds $15 \%$. This type of limitation on the solid solubility is frequently referred to as the size factor. Hume-Rothery ${ }^{(9)}$ has stated that in spite of the size factor of silver within a favourable range, the solid solubility of this element in iron is much restricted, because the $(4 \mathrm{~d})$ sub-group in the silver atom is very stable and does not interact with the (3d) electrons of the iron atom.

Since the average coordination number and the density will be lower at the grain boundary than in the

(6) K. Lücke and K. Detert: Acta Met., 5 (1957), 628.

(7) C. G. Fink and V.S. de Marchi: Trans. Electrochem. Soc., 74 (1938), 271.

(8) E. Raub and W. Plate: Z. Metallk., 40 (1949), 206.

(9) W. Hume-Rothery and G. V. Raynor: The Structure of Metals and Alloys, 216 (Richard Clay, London, 1954). interior of the crystal, such impurity atoms as silver having a low intragranular solubility will segregate preferentially at the grain boundary where they reduce the misfit energy. Therefore, the free energy of activation for the boundary migration will increase, thus resulting in the retardation of the normal grain growth. Assuming that the solubility of impurity atoms in the boundary is governed simply by geometrical considerations $^{(5)}$, the concentration of 0.005 to 0.01 at $\%$ silver would be necessary to saturate the grain boundaries.

\section{Conclusions}

(1) The high purity melt failed to undergo the secondary recrystallization.

(2) A considerable increase in the matrix grain size due to the normal growth was observed in the highpurity melt.

(3) The normal grain growth was effectively retarded, and a strong Goss texture was developed by the secondary recrystallization in the melt to which $0.018 \mathrm{wt} \%$ silver had been added.

(4) It is reconfirmed that primary matrix grains must be retained small in size to obtain complete a secondary recrystallization in the case of aluminum-iron.

(5) It is assumed that the free energy of activation for boundary migration of the matrix grains is increased by the segregation of silver atoms at lattice imperfections in the boundaries.

\section{Acknowledgements}

This work was performed at the Technical Research Laboratory, Kawasaki Steel Corporation, Kqbe. The authors wish to thank Dr. Isamu Goto and Mr. Kazuo Tsuruoka for their helpful suggestions. The authors also express their appreciation to Prof. Hideo Takaki of Kyoto University for his valuable comments on the manuscript. 